\title{
Nitrate Removal from Waste-Water Using Silica Nanoparticles
}

\author{
Phuong Kim To, ${ }^{1}$ Hoa Thai Ma, ${ }^{2}$ Lam Nguyen Hoang, ${ }^{3}$ and Tan Tai Nguyen ${ }^{4}{ }^{4}$ \\ ${ }^{1}$ School of Medicine and Pharmacy, Tra Vinh University, Tra Vinh City 87000, Vietnam \\ ${ }^{2}$ Department of Activated Polymer and Nano Materials Applications, School of Applied Chemistry, Tra Vinh University, \\ Tra Vinh City 87000, Vietnam \\ ${ }^{3}$ Biotechnology and Environment Center, School of Agriculture and Aquaculture, Tra Vinh University, \\ Tra Vinh City 87000, Vietnam \\ ${ }^{4}$ Department of Materials Science, School of Applied Chemistry, Tra Vinh University, Tra Vinh City 87000, Vietnam
}

Correspondence should be addressed to Tan Tai Nguyen; nttai60@tvu.edu.vn

Received 16 September 2020; Revised 4 November 2020; Accepted 24 November 2020; Published 10 December 2020

Academic Editor: Sre Ko I. Kirin

Copyright (c) 2020 Phuong Kim To et al. This is an open access article distributed under the Creative Commons Attribution License, which permits unrestricted use, distribution, and reproduction in any medium, provided the original work is properly cited.

\begin{abstract}
This work presented the removal of nitrate ions in aqueous solution based on silica nanoparticles (SiNPs), which were extracted from rice husk ash. The optimal conditions for nitrate ion adsorption were studied including $\mathrm{pH}$, contact time, adsorbate concentration, and amount of absorbance. The surface morphological analysis showed that the SiNPs extracted (purity of 98\%) were around $50 \mathrm{~nm}$ with a surface area of $30 \mathrm{~m}^{2} \cdot \mathrm{g}^{-1}$ and adsorption average pore width of $2.72 \mathrm{~nm}$, offers possibility for high capability of nitrate ion removal. The experimental results showed that the nitrate ion capability of adsorption was obtained around $14.22 \mathrm{mg} \cdot \mathrm{g}^{-1}$ with a concentration range from 0 to $25 \mathrm{mg} \cdot \mathrm{L}^{-1}$ based on optimizing conditions including $\mathrm{pH} 6$, contact time of 50 minutes, and SiNP dosage of $0.15 \mathrm{~g} \mathrm{vol}^{-1}$. In addition, nitrate ion removal based on SiNPs will provide considerate benefits such as the reducing costly sample pretreatment steps, less time-consuming, and reliable methods for processing nitratepolluted water.
\end{abstract}

\section{Introduction}

Nowadays, pollution of surface water by nitrate is serious problem. Using large amount of artificial fertilizers has caused the penetration of nitrates into the surface water. An increase in amount of nitrate may be associated with the increment of aquatic organism that caused water eutrophication [1]. Recently, several methods for removal of nitrogen ions in wastewater have been reported including wetland treatment system [2-4], electrodialysis [5-10], electrochemical reaction [11-16], bioreactor system [17], integration between electrodialysis and electrolysis $[18,19]$, catalytic oxidation-removal process [20], and anion exchange resin [21]. However, those methods seem not to be suitable for the elimination of nitrate ions due to their significant disadvantages such as complication in operation, subsequent disposal problem of the generated nitrate waste brine, and expensive and timeconsuming method.
A few decades ago, adsorption processing has been investigated and widely applied for removal of nitrate ions in waste-water due to its benefits, i.e., high adsorption capacity, ease-of-use, and environmentally friendly method. For examples, several adsorption materials have been used for nitrate ion removal such as coal-fired blue gas [20], soil profiles and sediments [22], and sawdust [23-25]. However, these materials needed the pretreatment for the removal process. Therefore, it is worth to consider that silica nanoparticles (SiNPs) are promising material for removal of heavy metals [26-28] with high adsorption capability. In addition, the rice husk ash (RHA), which contains high amount of silica (approximately 90\%), is the by-product of a brick-kiln industry. So, the reuse and recycling process of RHA for extraction of SiNPs is a cost-effective and environmental friendly method.

This work was designed to investigate the adsorption process of nitrate ions utilizing SiNPs, which was extracted 
from RHA. The physicochemical properties of the adsorbent were investigated, and the adsorption conditions were optimizing based on controllable parameters including $\mathrm{pH}$, adsorbent dosage, concentration of adsorbate, and contact time.

\section{Materials and Methods}

2.1. Chemicals and Reagents. The rice husk ash was collected from the brick-kiln industry (Tra Vinh Province, Vietnam). Hydrochoric acid $(\mathrm{HCl}, 98 \%)$, sodium hydroxide $(\mathrm{NaOH})$, sulfuric acid $\left(\mathrm{H}_{2} \mathrm{SO}_{4}, 98 \%\right)$, sodium salicylate $\left(\mathrm{C}_{7} \mathrm{H}_{5} \mathrm{NaO}_{3}\right.$, $99.5 \%)$, postassium nitrate $\left(\mathrm{KNO}_{3}, 99 \%\right)$, and postassium sodium tartrate tetrahydrate $\left(\mathrm{C}_{4} \mathrm{H}_{4} \mathrm{KNaO}_{6} .4 \mathrm{H}_{2} \mathrm{O}, 99.5 \%\right)$ were purchased from Sigma-Aldrich.

2.2. Extraction Process of SiNPs. SNPs were extracted from RHA based on the sol-gel method. The extraction process could be briefly described: firstly, RHA of $2 \mathrm{~g}$ was collected from the brick-kiln industry, then washed with DI water for removal of dirt, and then soaked in the sodium hydroxide solvent $(3.5 \mathrm{M})$ under stirring at the speed of $400 \mathrm{rpm}$ to generate sodium silicate. The RHA-induced sodium silicate filtrated to remove the nonreactive impurities. Finally, the sodium silicate solution obtained was cooled at room temperature and added to hydrochloric acid (4 M) under vigorous stirring in order to initiate the hydrolysis-condensation reaction at $\mathrm{pH} 7$. The gel obtained was then dispersed in ethanol, washed with distilled water (three times), and dried at $110^{\circ} \mathrm{C}$ for $2 \mathrm{~h}$ to remove remaining surfactants. The SNPs synthesized were stored in desiccator for further characterizations [28].

2.3. Adsorption Process for Nitrate Ion Removal. In this study, SiNPs were generated from the rice husk ash based on the sol-gel method [28] and utilized for nitrate removal. An adsorption capability of nitrate was investigated based on the controllable parameters including contact time, $\mathrm{pH}$, adsorbent's mass, and concentration at room temperature. In addition, $\mathrm{pH}$ was varied from 4 to 8 , and contact time changed from 20 to 60 minutes with an increment of $10 \mathrm{~min}$ each. Nitrate concentration was set from 5 to $20 \mathrm{mg} \cdot \mathrm{L}^{-1}$, and adsorbent's mass changed from 0.05 to $0.2 \mathrm{~g}$. The concentration of nitrate ions was analyzed by using a UV-Vis spectrum analyzer. The standard nitrate ion was generated by mixing sodium salicylate $(0.5 \mathrm{~mL})$, postassium sodium tartrate tetrahydrate $(10 \mathrm{~mL})$, and sodium hydroxide $(2.5 \mathrm{~mL})$. The capacity of adsorption $\left(q_{\text {cap }}\right)$ was estimated based on the following equation [29]:

$$
q_{\text {cap }}=\frac{C_{\text {beg }}-C_{\text {fin }}}{m_{\text {SiNPs }}} V \text {, }
$$

where $C_{\text {beg }}$ is the nitrate ions' initial concentration, $C_{\mathrm{fin}}$ is the concentration of nitrate ions at the equilibrium state, $m_{\text {SiNPs }}$ is the adsorbent's mass, and $V$ is the adsorbate's volume.

\section{Results and Discussion}

SiNPs were generated from rice husk ash, and physicochemical properties were characterized by the Fourier transform infrared spectroscopy (FTIR), scanning electronic microscopy (SEM), and energy dispersive X-ray spectroscopy (EDS). The results showed that the absorption bands were obtained at 1069 and $794 \mathrm{~cm}^{-1}$, which corresponded to the symmetric and asymmetric components of $\mathrm{Si}-\mathrm{O}-\mathrm{Si}$ variation as shown in Figure 1(a) [28]. The irregular shapes of SiNPs with a diameter of around $50 \mathrm{~nm}$ were achieved by SEM as depicted in Figure 1(b). In addition, the main elements were comprising of $\mathrm{Si}, \mathrm{O}$, and $\mathrm{Na}$ (Figure $1(\mathrm{c})$ ) with weight concentrations of 23,75 , and $2 \%$, respectively. The small amount of $\mathrm{Na}$ remained was due to unperfect process of washing. A combined analysis to determine materialspecific surface, pore size distribution, total pore area, and total pore volume (BET and $\mathrm{BJH}$ analysis) indicated that SiNPs possessed a surface area of $36 \mathrm{~m}^{2} \mathrm{~g}$ with an averaged pore size of $2.72 \mathrm{~nm}$ (Figure 1(d)), leading to considerate that this material may provide a potential application for nitrate elimination.

The capacity of adsorption ( $\mathrm{mg}^{-1} \mathrm{~g}^{-1}$ ) for nitrate ion removal based on SiNPs was studied by investigation the influence of $\mathrm{pH}$, adsorbent mass, and contact time. It was noted that the stirring velocity of $400 \mathrm{rpm}$ and initial concentration of nitrate ions of $20 \mathrm{ppm}$ were remained during the experimental process. It should be noted that each data point in Figures 2(a) and 2(b) and Figure 3 is represented by the mean value of three experimental results. As seen in Figure 2(a), the capability of adsorption reached a maximum value of $4.95 \mathrm{mg} \cdot \mathrm{g}^{-1}$ at $\mathrm{pH} 6$, while the capability of adsorption dropped down when $\mathrm{pH}$ value was higher or lower than 6. At $\mathrm{pH}<6$, Figure 2(a) also presents a low adsorption capability due to chemical decomposition of $\mathrm{NO}_{3}^{-}$in the form of $\mathrm{N}_{2} \mathrm{O}$. For $\mathrm{pH}>6$, the loss of $\mathrm{NO}_{3}^{-}$was caused by the decomposition of $\mathrm{NO}_{3}^{-}$in the form of $\mathrm{N}_{2}$ and to a lesser extent of $\mathrm{N}_{2} \mathrm{O}$ [30]. When the $\mathrm{pH}$ of the aqueous solution increased or decreased, the chemical transformation of $\mathrm{NO}_{3}^{-}$ may prevent the adsorption of nitrate. This leads to obtain more significant capacity of absorption at $\mathrm{pH} 6$.

Table 1 represents the kinetic parameters for nitrate elimination. The fitting equation $P=P_{o}+A x+B x^{2}$ with parabolic shape was used to fit the experimental data obtained based on the investigation of $\mathrm{pH}$ (Figure 2(a)), mass of SiNPs (Figure 2(b)), and contact time (Figure 3) throughout the adsorption process [29]. The fitting results showed that the lowest capacity of adsorption $\left(P_{o}\right)$ was $1.19 \mathrm{mg} \cdot \mathrm{g}^{-1}$ for $\mathrm{pH}$ change, $4.0 \mathrm{mg} \cdot \mathrm{g}^{-1}$ for mass of SiNPs change, and $4.81 \mathrm{mg} \cdot \mathrm{g}^{-1}$ for contact time change as depicted in Table 1. In the case of $\mathrm{pH}$, the capacity of adsorption obtained was 4 times lower than that of other cases (mass and contact time). This may rely on the chemical transformation of $\mathrm{NO}_{3}^{-}$as mentioned above. Additionally, the equation was fitted well with the experimental data, due to its large correlation coefficients $\left(R^{2}\right)$.

The adsorption kinetics of nitrate ions based on SiNPs were investigated. Figure 3 presents that the optimizing adsorption capacity of $4.96 \mathrm{mg} \cdot \mathrm{g}^{-1}$ was obtained with the 


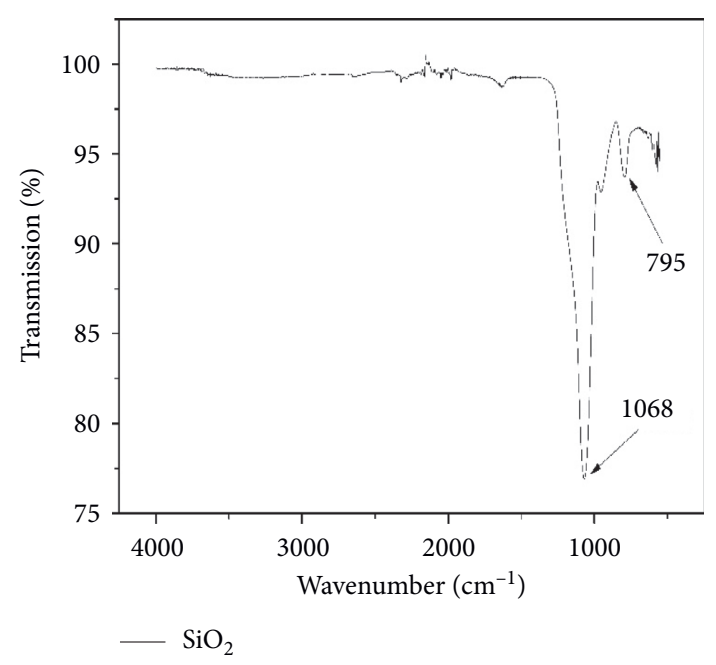

(a)

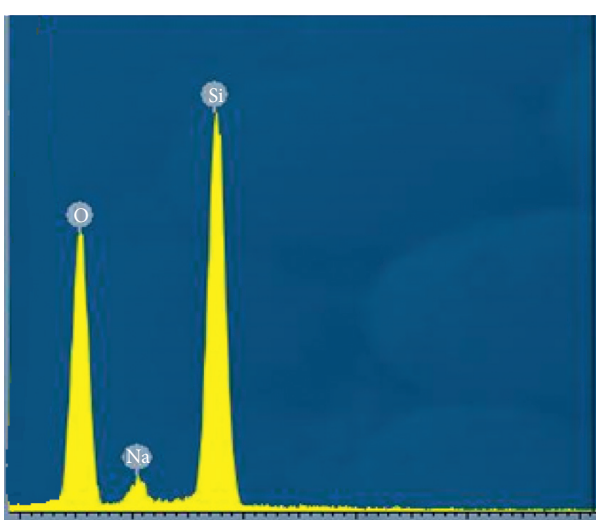

(c)

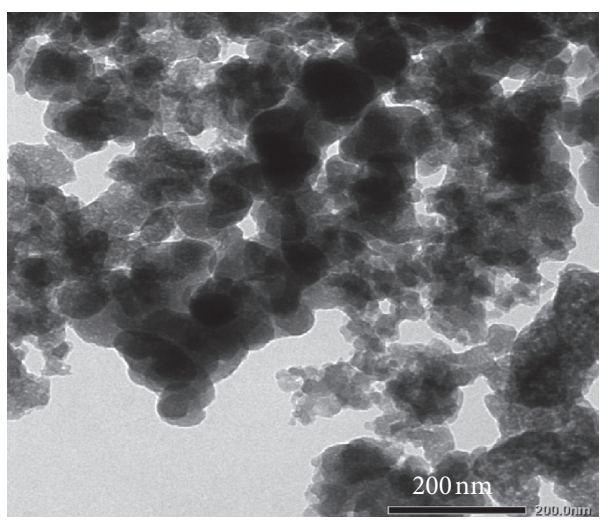

(b)

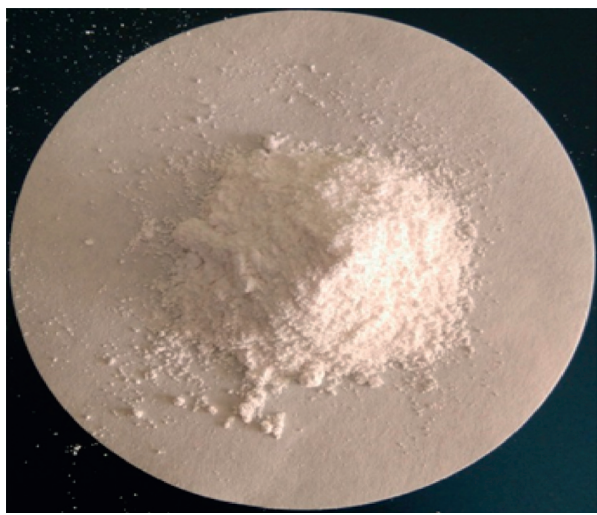

(d)

FIGURE 1: SiNP characterization based on Fourier transform infrared spectrum (a); SEM image (b); EDS composition analysis of SiNPs (c); and SiNPs extracted from RHA (d).

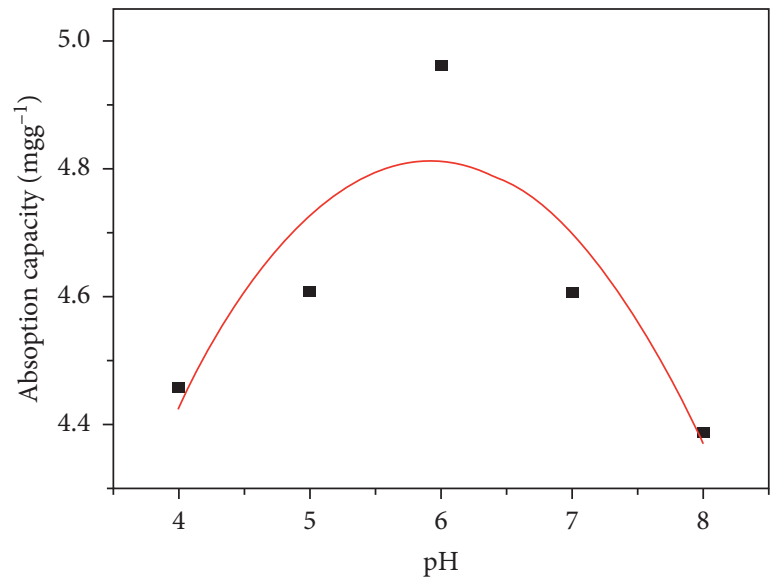

(a)

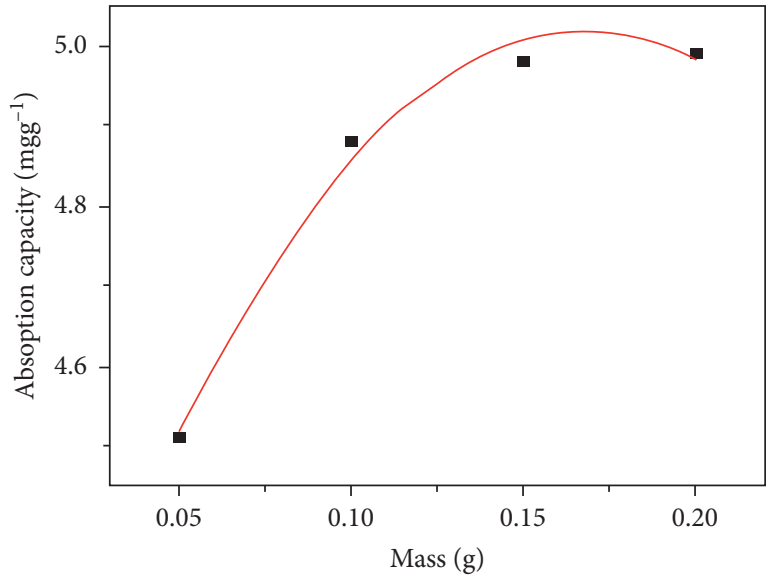

(b)

FIGURE 2: Influence of $\mathrm{pH}$ (a) and mass of SiNPs (b) to the capacity of adsorption of nitrate ions.

optimized conditions including a SiNP mass of $0.15 \mathrm{~g}$ and contact time of $50 \mathrm{~min}$. The nitrate ions were adsorbed by SiNPs and got a saturation at $50 \mathrm{~min}$. The longer time of adsorption was achieved due to the low initial adsorption rate of around $0.244\left(\mathrm{mg} \cdot \mathrm{min}^{-1}\right)$. It is noted that the lower the initial adsorption rate is, the longer the equilibrium time is. This relatively low adsorption rate can be attributed to weak diffusion of nitrate ions from surface adsorption sites 


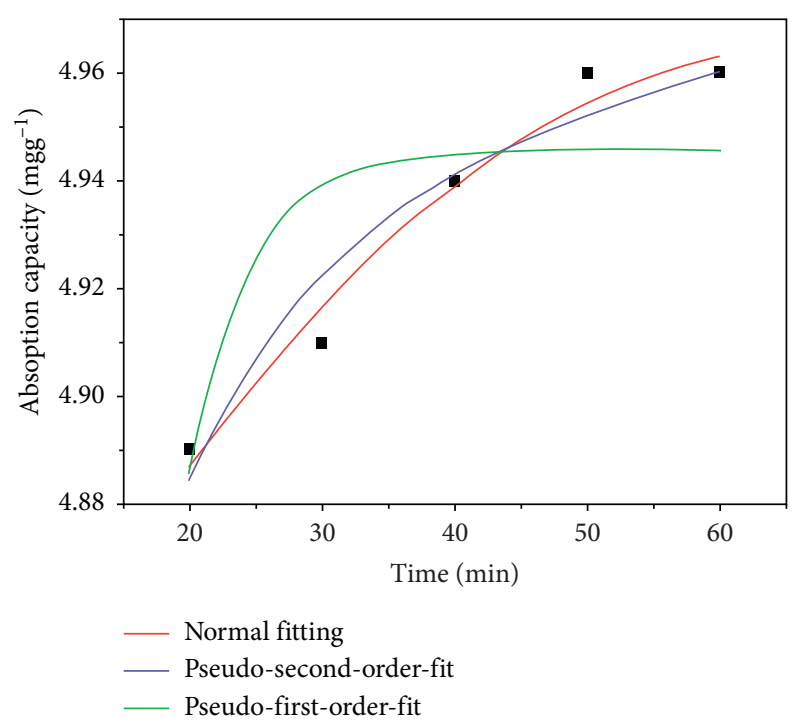

Figure 3: Adsorption kinetics of nitrate ions by SiNPs.

TABLE 1: Kinetic coefficients for nitrate removal.

\begin{tabular}{lccr}
\hline & \multirow{2}{*}{ Minimum capacity of adsorption $P_{o}\left(\mathrm{mg} \mathrm{g}^{-1}\right)$} & Fitting parameters & \multicolumn{2}{c}{$B($ a.u. $)$} & $R^{2}$ \\
\hline Time & 4.81 & 0.01 & -3.57 \\
Mass & 4.0 & 12.08 & -36 \\
pH & 1.19 & 1.22 & -0.95 \\
\hline
\end{tabular}

to the bulk SiNP pore, mainly caused by the small pore size of $2.71 \mathrm{~nm}$. Moreover, the adsorption kinetics were studied based on the pseudo-first-order kinetic model (equation (2)) and the pseudo-second-order kinetic model (equation (3)) as follows [30]:

$$
\begin{aligned}
& P_{t}=P_{\mathrm{ad}}\left(1-e^{-L_{1} t}\right), \\
& P_{t}=\frac{t}{\left(1 / L_{2} P_{\mathrm{ad}}^{2}\right)+\left(t / P_{\mathrm{ad}}\right)},
\end{aligned}
$$

where $P_{\text {ad }}$ and $P_{t}$ were the capacity of adsorption at the saturation time and $t$, respectively. $L_{1}$ and $L_{2}$ were the first and second pseudo-order rate constants, respectively. The first and second pseudokinetic models represented the kinetics of the solid-liquid system based on adsorption of mononuclear and binuclear, respectively. Table 2 represents the adsorption parameters achieved based on the kinetic equations, while the comparison between the fitting equation and two pseudomodels is revealed in Figure 3. The capacity of adsorption was estimated around $5.0 \mathrm{mg} \cdot \mathrm{g}^{-1}$ as seen in Table 2 . This result was comparable for both models including the first and second pseudokinetic models and the parabolic one, indicating that three models fitted well into the experimental data. However, the correlation coefficient $\left(R^{2}\right)$ for the case of the parabolic fitting was higher than that of others (the first and second pseudokinetic models), indicating that the parabolic model was more suitable for prediction model of nitrate adsorption.
Our next step is to design adsorption system and adsorption isotherm models for the prediction procedures. Besides, the capacity of adsorption was proved to be also affected by the amount of adsorbent. In this investigation, the nitrate concentration was changed from 5 to $25 \mathrm{mg} \cdot \mathrm{L}^{-1}$ with experimental conditions optimized at SiNP mass of $0.15 \mathrm{~g}, \mathrm{pH} 6$, and contact time $50 \mathrm{~min}$. The Langmuir (equation (4)) and Freundlich (equation (5)) models were utilized to analyze the data [31]:

$$
\begin{gathered}
C_{\mathrm{eq}}=\frac{P_{\mathrm{eq}}}{E_{L}\left(P_{\mathrm{max}}-P_{\mathrm{eq}}\right)}, \\
\log P_{\mathrm{eq}}=I \log C_{\mathrm{eq}}+\log E_{F},
\end{gathered}
$$

where $C_{\mathrm{eq}}, P_{\mathrm{eq}}$, and $P_{\max }$ were the concentration of nitrate ion, the capacity of adsorption at saturated state, and the maximum capacity of adsorption, respectively; $E_{L}$ was the adsorption energy; $I$ was the intensity of the adsorption; and $E_{F}$ was the affinity of adsorption. As shown in Table 3, the affinity between SiNPs and nitrate ions was estimated around $4.85 \mathrm{~L} \cdot \mathrm{mg}^{-1}$ exhibited strong interaction between nitrate ions and SiNP surface. Especially, the larger the $E_{L}$ is, the stronger the affinity of nitrate ions on the surface of SiNPs is. In addition, the adsorption intensity of $(I)$ of 0.75 was obtained based on the Freundlich model (Figure 4(b)). This intensity value was lower than 1 , resulted in low speed in adsorption of nitrate ions as discussed above [29]. Unlike the Freundlich isotherm, the Langmuir isotherm was an empirical model which implied a maximum adsorption 
TABLE 2: Adsorption coefficients for kinetic models.

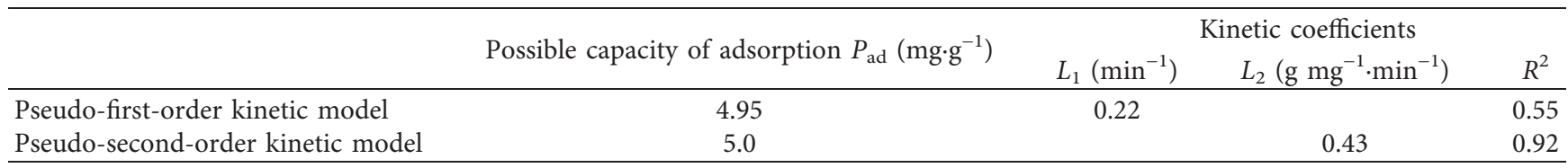

TABLE 3: Adsorption isotherm parameters for nitrate ion removal.

\begin{tabular}{|c|c|c|c|c|c|}
\hline & \multirow{2}{*}{ Maximum adsorption capacity $P_{\max }\left(\mathrm{mg} \cdot \mathrm{g}^{-1}\right)$} & \multicolumn{4}{|c|}{ Isotherm coefficients } \\
\hline & & $E_{F}\left(\mathrm{mg} \cdot \mathrm{g}^{-1}\right)$ & $I$ & $E_{L}\left(\mathrm{~L} \cdot \mathrm{mg}^{-1}\right)$ & $R^{2}$ \\
\hline Freundlich isotherm & & 0.49 & 0.75 & & 0.97 \\
\hline Langmuir isotherm & 14.22 & & & 4.85 & 0.96 \\
\hline
\end{tabular}

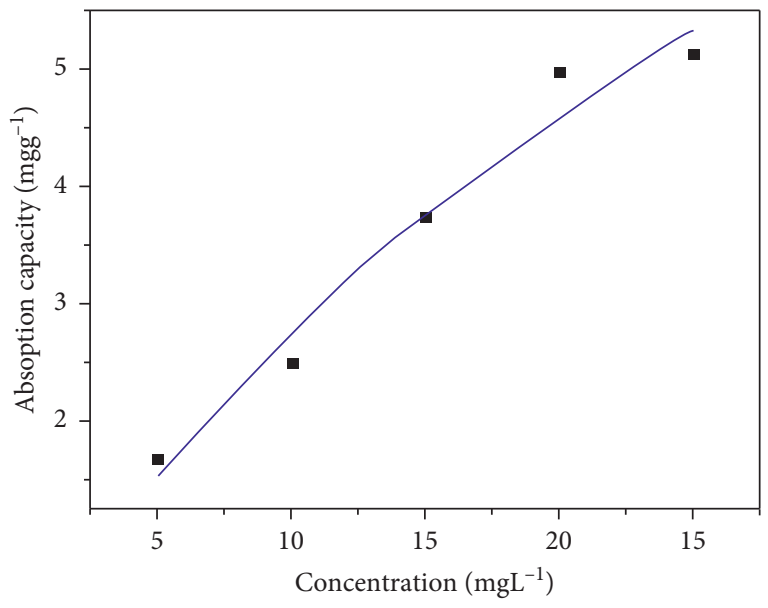

(a)

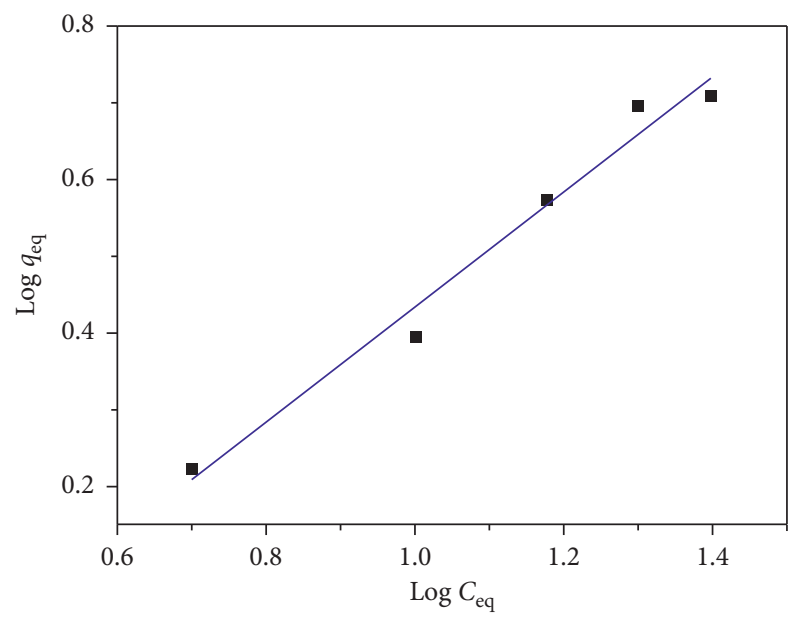

(b)

Figure 4: Langmuir isotherm model (a) and Freundlich isotherm model (b) for nitrate ion removal by SiNPs.

capacity of the adsorbent. The Langmuir isotherm analysis in Figure 4(a) exhibited a maximum adsorption capacity of $14.22 \mathrm{mg} \cdot \mathrm{g}^{-1}$, indicating that the ability to adsorb nitrate ions of SiNPs was an effective method to discard nitrate from waste-water.

\section{Conclusions}

In conclusion, the nitrate ions can be removed from aqueous solution by SiNPs extracted from rick husk ash. The amount of nitrate removed and the removal effect will depend on various factors such as $\mathrm{pH}$, mass of adsorbent, concentration of adsorbate, and contact time. The experimental results showed that the maximum adsorption capacity of $14.22 \mathrm{mg}$ SiNPs/g nitrate ions was achieved at $\mathrm{pH}$ 6, SiNP mass of $0.15 \mathrm{~g}$, and contact time of $50 \mathrm{~min}$. The capacity of adsorption can be enhanced by the modification of the SiNP surface with functional groups. In addition, the utilization of SiNPs for removal of nitrate ions not only provides an easeof-use method, but also low cost adsorbent.

\section{Data Availability}

This data used to support the findings of this study are available from the corresponding author upon request.

\section{Conflicts of Interest}

The authors declare no conflicts of interest regarding this work.

\section{Acknowledgments}

This research was supported by Tra Vinh University under Basic Science Research.

\section{References}

[1] A. Ugurlu and B. Salman, "Phosphorus removal by fly ash," Environment International, vol. 24, no. 8, pp. 911-918, 1998.

[2] T. L. Ingersoll and L. A. Baker, "Nitratfe removal in wetland microcosms," Water Research, vol. 32, no. 3, pp. 677-684, 1998.

[3] M. J. Busnardo, R. M. Gersberg, R. Langis, T. L. Sinicrope, and J. B. Zedler, "Nitrogen and phosphorus removal by wetland mesocosms subjected to different hydroperiods," Ecological Engineering, vol. 1, no. 4, pp. 287-307, 1992.

[4] M. E. Karpuzcu and W. T. Stringfellow, "Kinetics of nitrate removal in wetlands receiving agricultural drainage," Ecological Engineering, vol. 42, pp. 295-303, 2012.

[5] A. E. Midaoui, F. Elhannouni, M. Taky et al., "Optimization of nitrate removal operation from ground water by 
electrodialysis," Separation and Purification Technology, vol. 29, no. 3, pp. 235-244, 2002.

[6] A. Kapoor and T. Viraraghavan, "Nitrate removal from drinking water-review," Journal of Environmental Engineering, vol. 123, no. 4, pp. 371-380, 1997.

[7] F. Lutin and G. Guerif, "Electrodialysis applied to denitration of drinking water," Water Treatment and Pervaporation, vol. 189, pp. 200-208, 1982.

[8] R. Rautenbach, W. Kopp, R. Hellekes, R. Peter, and G. Vanopbergen, "Separation of nitrate from well water by membrane processes (reverse osmosis/electrodialysis reversal)," Aqua, vol. 5, pp. 279-282, 1986.

[9] J. P. Van Der Hoek, A. B. Griffioen, and A. Klapwijk, "Biological regeneration of nitrate loaded anion exchange resins by denitrifing bacteria," Journal of Chemical Technology Biotechnology, vol. 43, no. 3, pp. 213-222, 1988.

[10] M. Oldani, E. Killer, A. Miguel, and G. Schock, "On the nitrate and monovalent cation selectivity of ion exchange membranes used in drinking water purificationfication," Journal of Membrane Science, vol. 75, no. 3, pp. 265-275, 1992.

[11] A. S. Koparal and Ü. B. Ögütveren, "Removal of nitrate from water by electroreduction and electrocoagulation," Journal of Hazardous Materials, vol. 89, no. 1, pp. 83-94, 2002.

[12] M. Paidar, I. Rousar, and K. Bouzek, "Electrochemical removal of nitrate ions in waste solutions after regeneration of ion exchange columns," Journal of Applied Electrochemistry, vol. 29, no. 5, pp. 611-617, 1999.

[13] O. A. Petrii and T. Y. Safonova, "Electroreduction of nitrate and nitrite anions on platinum metals: a model process for elucidating the nature of the passivation by hydrogen adsorption," Journal of Electroanalytical Chemistry, vol. 331, no. 1-2, pp. 897-912, 1992.

[14] K. Kneifel and G. Luhrs, "Nitrate removal by electrodialysis for brewing water," Desalination, vol. 68, no. 2-3, pp. 203-209, 1988.

[15] H. L. Li, D. H. Robertson, J. Q. Chambers, and D. T. Hobbs, "Electrochemical reduction of nitrate and nitrite in concentrated sodium hydroxide at platinum and nickel electrodes," Journal of the Electrochemical Society, vol. 135, no. 5, pp. 1154-1158, 1988.

[16] R. Tenne, K. Patel, K. Hashimoto, and A. Fujishima, "Efficient electrochemical reduction of nitrate to ammonia using conductive diamond film electrodes," Journal of Electroanalytical Chemistry, vol. 347, no. 1-2, pp. 409-415, 1993.

[17] M. Shrimali and K. P. Singh, "New methods of nitrate removal from water," Environmental Pollution, vol. 112, no. 3, pp. 351-359, 2001.

[18] A. A. Shady, C. Peng, J. Bi, and H. Xu Jao, "Recovery of Pb (II) and removal of $\mathrm{NO}_{3}^{-}$from aqueous solutions using integrated electrodialysis, electrolysis, and adsorption process," Desalination, vol. 286, pp. 304-315, 2012.

[19] M. A. Menkouchi Sahli, S. Annouar, M. Mountadar, A. Soufiane, and A. Elmidaoui, "Nitrate removal of brackish underground water by chemical adsorption and by electrodialysis," Desalination, vol. 227, no. 1-3, pp. 327-333, 2008.

[20] J. Ding, Q. Zhong, S. Zhang, F. Song, and Y. Bu, "Simultaneous removal of $\mathrm{NO}_{\mathrm{X}}$ and $\mathrm{SO}_{2}$ from coal-fired flue gas by catalytic oxidation-removal process with $\mathrm{H}_{2} \mathrm{O}_{2}$," Chemical Engineering Journal, vol. 243, pp. 176-182, 2014.

[21] J. Dron and A. Dodi, "Comparison of adsorption equilibrium models for the study of $\mathrm{CL}^{-}, \mathrm{NO}_{3}^{-}$and $\mathrm{SO}_{4}^{2-}$ removal from aqueous solutions by an anion exchange resin," Journal of Hazardous Materials, vol. 190, no. 1-3, pp. 300-307, 2011.
[22] R. M. Engler and W. H. Patrick, "Nitrate removal from floodwater overlying flooded soils and sediments," Journal of Environmental Quality, vol. 3, no. 4, 1974.

[23] W. D. Robertson, G. I. Ford, and P. S. Lombardo, "Woodbased filter for nitrate removal in septic systems," Transactions of the ASAE, vol. 48, no. 1, pp. 121-128, 2005.

[24] W. D. Lombardo, C. J. Ptacek, and S. J. Brown, "Aquifer nitrate and perchlorate remediation using a wood particle layer," GroundWater Monitoring and Remediation, vol. 27, pp. 85-95, 2007.

[25] W. D. Robertson, C. J. Ptacek, and S. J. Brown, "Rates of nitrate and perchlorate removal in a 5-year-old wood particle reactor treating agricultural drainage," Ground Water Monitoring \& Remediation, vol. 29, no. 2, pp. 87-94, 2009.

[26] G. Renard, M. Mureseanu, A. Galarneau, D. A. Lerner, and D. Brunel, "Immobilisation of a biological chelate in porous mesostructured silica for selective metal removal from wastewater and its recovery," New Journal of Chemistry, vol. 29, no. 7, pp. 912-918, 2005.

[27] M. Mureseanu, N. Cioatera, I. Trandafir, I. Georgescu, F. Fajula, and A. Galarneau, "Selective $\mathrm{Cu} 2+$ adsorption and recovery from contaminated water using mesoporous hybrid silica bio-adsorbents," Microporous and Mesoporous Materials, vol. 146, no. 1-3, pp. 141-150, 2011.

[28] T. T. Nguyen, H. T. Ma, P. Avti et al., "Adsorptive removal of Iron using $\mathrm{SiO}_{2}$ nanoparticles extracted from rice husk ash," Journal of Analytical Methods in Chemistry, vol. 2019, Article ID 6210240, 8 pages, 2019.

[29] N. H. Lam, H. T. Ma, M. J. K. Bashir, G. Eppe, P. Avti, and T. T. Nguyen, "Removal of phosphate from wastewater using coal slag," International Journal of Environmental Analytical Chemistry, vol. 2020, pp. 1-11, 2020.

[30] D. Panias, I. P. Giannopoulou, and T. Perrak, "Effect of synthesis parameters on the mechanical properties of fly ashbased geopolymers," Colloids Surface A: Physicochemical and Engineering Aspects, vol. 301, no. 1-3, pp. 246-254, 2006.

[31] M. Šešlija, A. Rosić, N. Radović, M. Vasić, M. Đogo, and M. Jotić, "Properties of fly ash and slag from the power plants," Geologia Croatica, vol. 69, no. 317, 2016. 